\title{
Pesquisa-experiência em educação ambiental: exercícios (eco)lógicos para gestão dos resíduos
}

\author{
Research-experience in environmental education: (eco)logical \\ exercises for waste management
}

\author{
Daniel Dall'Igna Ecker ${ }^{1}$
}

Resumo

O presente texto compartilha o resultado de uma pesquisa-experiência sobre exercícios (eco)lógicos possíveis de autoeducação ambiental, para gestão dos resíduos humanos. Com foco na transformação do pesquisador e de sua relação com a gestão de resíduos, baseou-se em três etapas: observações sistemáticas em uma avenida da cidade de Porto Alegre e em uma universidade privada; busca de informações sobre a gestão de resíduos na internet (plataforma Google) e em uma biblioteca universitária; imersão do pesquisador em uma associação de separação do lixo e realização de entrevista com a responsável pelo local. Inspirada em produções de conhecimento pós-estruturalistas, a noção de pesquisa-experiência emerge enquanto possibilidade de tatear elementos e fabricar objetos para o pensamento, neste caso, como via de autotransformação do pesquisador na sua relação com a gestão de resíduos. Como resultado, fora possível articular a vivência da experiência com a pesquisa sobre o meio ambiente, refletindo sobre os paradigmas educativo-ambientais e as ideologias de consumo e individualismo que permeiam o cotidiano humano. Através de elementos emergentes no campo da pesquisa, colocou-se em análise a educação ambiental, considerando-a via de transformação das (eco)lógicas cotidianas, alguns de seus impasses, como os aspectos subjetivos ou estruturais que envolvem uma autoeducação ambiental.

Palavras-chave: Pesquisa-experiência. Educação ambiental. Lixo. Gestão de resíduos.

\begin{abstract}
The present text shares the result of a research-experience about possible (eco)logical exercises of environmental self-education, for human waste management. Focusing on the transformation of the researcher and its relationship with waste management, was based on three steps: systematic observations in an avenue of the city of Porto Alegre and in a private university; search for information on waste management on the internet (Google platform) and in a university library; immersion of the researcher in a garbage separation association and an interview with the person in charge of the place. Inspired by poststructuralist knowledge production, the notion of research-experience emerges as a possibility of groping elements and fabricating objects for thought, in this case, as a way of self-transformation of the researcher in its relationship with waste management. As a result, it was possible to articulate the experience of the experiment with the research on the environment, reflecting on the educationalenvironmental paradigms and the ideologies of consumption and individualism that permeate human daily life. Through emerging elements in the field of research, environmental education was analyzed as a way of transforming everyday (eco)logics, some of its impasses, such as the subjective or structural aspects that involve environmental self-education.
\end{abstract}

Key words: Research-experience. Environmental education. Garbage. Waste Management.

1 Doutorando (Bolsista CAPES) no Programa de Pós-Graduação em Psicologia Social e Institucional (PPGPSI) da Universidade Federal do Rio Grande do Sul (UFRGS), RS, Brasil. E-mail: daniel.ecker@hotmail.com 


\section{Introdução}

Quando a última árvore tiver caído, quando o último rio tiver secado, quando o último peixe for pescado, vocês vão entender que dinheiro não se come

Provérbio dos Índios Sioux (HARTMANN, 2017, p. 4).

O presente texto compartilha o resultado de uma pesquisa-experiência ${ }^{2}$ sobre exercícios (eco)lógicos possíveis de autoeducação ambiental, para gestão dos resíduos humanos. Com foco na transformação do pesquisador e de sua relação com a gestão de resíduos, propõe pensar sobre as possibilidades de ações no campo da educação ambiental. Para isso, articula os materiais advindos da pesquisaexperiência com reflexões de autores e autoras do campo, analisando elementos que envolvem os seres humanos e paradigmas educativosambientais, o individualismo e consumismo, assim como, aspectos subjetivos e estruturais envolvidos na transformação de (eco)lógicas cotidianas.

A proposta da pesquisa-experiência emerge em um contexto mundial que evidencia florestas sendo devastadas, o aquecimento das cidades cada vez mais insuportável, animais desaparecendo, outros multiplicando-se e desequilibrando o ciclo da natureza. Novas doenças surgindo, reservas naturais de águas cada vez mais escassas, a miséria crescendo, a competição e a violência, decorrentes das desigualdades e da superpopulação, se alastram. O consumo aumenta e a produção de resíduos extrapola o que a natureza é capaz de decompor. Apesar de muitas pessoas terem percebido que algo se altera no planeta, muitas veem esses acontecimentos como irrecuperáveis, naturais, aceitando-os como se fossem destinos nos quais não teríamos como modificar.

O exercício da educação ambiental emerge nessa problemática. Objetiva instigar as pessoas e ensiná-las a desenvolverem um sistema social mais sustentável, onde hajam recursos para os que querem usufruir, no presente, preservando para os que usufruirão no futuro. Contudo, a lógica da educação ambiental não perpassa todos os espaços sociais. Inúmeras filosofias do cotidiano são atravessadas por raciocínios perversos, constituídos historicamente, da relação dos seres humanos com a natureza: os ambientes naturais são compreendidos como objetos de posse humana, com os quais se teria total autorização e legitimidade para manipular como se queira, satisfazendo necessidades e desejos individuais humanos, acima de tudo (GRÜN, 2005).

$\mathrm{Na}$ vida cotidiana, não há como reverter todo o prejuízo à natureza que a existência humana, por si só, acarreta. Entretanto, é possível que pequenas mudanças na rotina diminuam o impacto e a velocidade com que essa degradação ocorre. Nesse raciocínio, se propôs este texto, que tem como objetivo compartilhar o resultado de uma pesquisa-experiência, sobre exercícios (eco) lógicos $^{3}$ possíveis de autoeducação ambiental, para gestão dos resíduos humanos. Em uma sociedade de controle, que supostamente prevê uma regulação e regulamentação da vida enquanto estratégia de disciplinarização dos corpos, buscou-se saber se a informação sobre a gestão dos resíduos humanos na cidade de Porto Alegre, Rio Grande do Sul, Brasil, é de fácil acesso quando se deseja auto educar-se (eco)

\footnotetext{
${ }^{2}$ A presente proposta integra pesquisas na área da Psicologia Social e Institucional de matriz pós-estruturalista, de base foucaultiana. Nelas, a produção de conhecimento reivindica uma epistemologia própria, já que não é contemplado pelas perspectivas tradicionalmente abordadas (HÜNING; SCISLESKI, 2018). Com isso, um dos aspectos de sua produção científica é a análise de elementos do presente, para a produção de pensamentos e não de verdades forjadas, sem compromisso direto com modelos científicos positivistas impostos por correntes hegemônicas. Assim, dentre os elementos que têm relevância nessa abordagem, destaca-se a produção de um conhecimento particular, política e historicamente localizado, que evidencia experiências territorialmente situadas, singulares e posicionadas éticamente.

${ }^{3}$ A separação e, ao mesmo tempo, proximidade entre a palavra eco e lógico, na escrita, visa dar ênfase à contribuição que a operacionalidade de raciocínios (eco)lógicos podem efetuar na conservação da natureza, seja no modo como administramos nossos comportamentos cotidianos, seja na forma como gerenciamos nossa produção de resíduos.
} 
logicamente: se a estrutura da cidade (como, por exemplo, a existência de latas de lixo diferenciadas) possibilita a auto conscientização para separação de resíduos; se há, realmente, caminhões de coleta seletiva que atuem pela cidade quando se quer mudar os próprios hábitos de gerenciamento do lixo; assim como, se existe informação de fácil acesso, sobre a diferenciação entre materiais recicláveis, reutilizáveis ou inutilizáveis, para quem objetiva aderir a separação do lixo como exercício cotidiano.

Sendo a Psicologia uma área de saber que, dentre sua amplitude, preocupa-se com o bemestar dos seres humanos, avalia-se a pertinência da presente discussão em prol do benefício coletivo, proposto via autotransformação. A educação ambiental, como tema amplo, direciona o recorte da pesquisa-experiência restringindo-se apenas a análise sobre a relação dos seres humanos com seus resíduos, os chamados 'lixos', a partir da proposta de autoeducação ambiental do próprio pesquisador, numa modificação da (eco)lógica cotidiana. Durante a existência, não há como evitar a produção de lixo, no entanto, tais resíduos muitas vezes não precisariam serem descartados. A industrialização acarretou em uma enorme contribuição para o aumento do lixo, principalmente, pelas embalagens que se tornaram cada vez mais descartáveis. Modos imperativos de comportamento, individualistas e consumistas, surgem como obstáculos às mudanças e requerem uma autoeducação ambiental pautada por transformações das (eco)lógicas do próprio cotidiano.

\section{Meio ambiente, seres humanos e paradigmas educativos-ambientais}

Em um passado, com fragmentos de ficção ${ }^{4}$, animais, plantas e terras eram vistas, predominantemente, como seres sagrados. Os seres humanos se compreendiam como habitantes de um único mundo, grupo de seres individuais, que se relacionavam enquanto organismos vivos interdependentes. Não haveria como alguém se perder na selva, afinal, os sujeitos faziam parte dela. Eles compunham a própria selva. A palavra natureza não existia enquanto categoria de diferenciação: os seres vivos formavam um todo integrado, correlacionados e intercontributivos. Com o passar dos anos, mudanças foram ocorrendo e concepções de natureza foram sendo criadas. Com predominância da natureza enquanto sinônimo de riqueza, seres relacionais e intercontributivos foram ganhando status diferenciados e valorativos. Matérias naturais se tornaram 'primas', com codinome de semimanufaturadas, submetidas à processos produtivos até tornarem-se produtos, literalmente, acabados. Fragilizou-se a natureza para satisfazer a necessidade, ou o mais puro desejo individual, não-necessariamente-necessário, dos humanos. Exploração e destruição tornaram-se novos significados do que seria meio ambiente.

Na contemporaneidade, o meio ambiente tornouse pauta que atrai atenção de uma ampla parcela da população. A sociedade percorre processos de sensibilização ecológica, cada vez estando mais ciente dos visíveis danos ao planeta, que estão ocorrendo devido destruição e desintegração socioambiental. Países, dos mais variados níveis de desenvolvimento, participam dessa devastação mundial que não exclui raças, ideologias, religiões, diferenças econômicas ou sociais (GRÜN, 2005). A cada sol que se põe, visibilizam-se os estragos que foram causados aos três elementos naturais do planeta: água, ar e terra. Urgências ambientais demandam necessidades de mudança, a responsabilização dos humanos fica mais evidente.

Contudo, apesar de vermos, com certa frequência, grandes alardes em busca de soluções para a questão ambiental, os processos educativos que ocorrem a partir do modo como se organizam os cotidianos

\footnotetext{
${ }^{4} \mathrm{O}$ exercício, nesse fragmento, de uma escrita ficcional enquanto estratégia metodológica tem como objetivo fabular e fabricar pensamentos envolvendo o tema em questão.
} 
humanos mantêm certa distância do assunto e, em alguns casos, não operam nenhuma iniciativa de conscientização. Grün (2005, p. 20) questiona “[...] como podemos ter uma educação não-ambiental se desde o dia de nosso nascimento até o dia de nossa morte vivemos em um ambiente?" O autor aposta que a dissociação entre humano e ambiente deriva da influência histórica de adaptação dos sistemas de ensino ao que se nomearia de 'ciência'. A intensa valorização do empirismo, com predominância da objetividade científica, transformou a natureza em objeto de estudo - sem qualidades sensíveis como cor, sabor, aroma - mas, sim, produto determinado como valor monetário a partir das suas possibilidades de uso.

Em uma lógica desumanizada, que compreende o habitat humano sem o próprio humano, afastando tudo aquilo que carece de respostas exatas ou de uma possível 'utilidade', os diferentes sistemas de ensino foram construídos a partir de concepções históricas que localizam ambiente e seres humanos como elementos desconexos. A preservação do meio ambiente, por exemplo, tornou-se sinônimo de proteção de animais não-humanos: florestas e outros seres e espaços externos às pessoas. Não vista como um exercício (eco)lógico que envolve os seres humanos e sua própria cidade, bairro, rua e, principalmente, sua própria casa, a atual compreensão de educação ambiental afasta o contexto humano de sua formulação conceitual (TAVARES; FREIRE, 2003).

Quando há sistemas racionais de ensino situando natureza e seres humanos como um 'todo' integrado, facilmente recaem numa 'teologização da natureza'. Essa, apela ao sagrado, interpretando que o ambiente fora criado por um ser superior, um ser bíblico ou místico, pregando crenças que, por vezes, afastam pessoas da aprendizagem sobre o cuidado ambiental (TAVARES, FREIRE, 2003). Para Soffiati (2008), dentre os fundamentos filosóficos e históricos para o exercício da ecocidadania e da ecoeducação, se destacaria a perspectiva educativa-ambiental que compreende os organismos vivos numa lógica harmônica, ecossistêmica, em que a interação e interdependência operam como processos positivos de produção de vidas. Se uma determinada área como, por exemplo, uma mata nativa, for substituída pelo cultivo de um único vegetal, compreende-se que essa monocultura afetará uma biodiversidade de organismos que coabitam esse sistema. Enquanto compreensão sistêmica, essa interferência acarretaria no comprometimento da cadeia alimentar dos animais que habitam a área, os quais produzem vida, tanto a partir da relação com as plantas existentes no local, quanto na relação com outros animais.

A dissociação entre humano e habitat, natureza e pessoas, e a classificação de seres vivos humanos e não-humanos, como espécies 'naturalmente' distintas, resultaram na materialização de significados cotidianos que orientam determinados modos das pessoas de pertencerem, agirem e estarem no mundo. Em uma lógica dos humanos como seres superiores, por isso diferenciados e de 'espécie' própria, o comportamento de uso da natureza para fins humanos relacionou-se à uma concepção das pessoas como resultado de uma espécie 'evoluída', portanto, passível de gerir o 'resto', que não estaria no seu patamar de evolução. Essa leitura, focada no humano numa perspectiva individualizada e valorativa, abre campos de possibilidade para comportamentos culturais predatórios, de consumo dos outros seres vivos, da busca em prol de benefícios e prazeres individuais, de ações voltadas apenas para a preservação de si enquanto humanos supostamente superiores.

\section{Seres humanos individualistas e suas culturas ideológicas de consumo}

Em um passado ocidental relativamente remoto, a igreja católica exercia intenso controle sobre as pessoas, Deus era o ser superior que organizava os seres humanos para disseminar e materializar sua palavra. Com os movimentos renascentistas, a categoria 'indivíduo' passa a ser constituída enquanto 
valor, referindo um sujeito que não queria mais ser submetido a um Deus e se colocava cada vez mais no centro do universo. Natureza e sua diversidade de organismos não eram mais compreendidas pela ideia Aristotélica de "[...] algo animado e vivo, na qual as espécies procuravam realizar seus fins naturais" (LIPOVETSKY, 2005, p. 27). Natureza, quase como um cenário inanimado, montado para o espetáculo que tinha os humanos como personagens principais, marca a mecanicidade e frieza com que pessoas começam a estabelecer relação com o meio ambiente. Autonomia e individualismo tornaram-se imperativos. Valorizados enquanto metas a serem alcançadas, ser autônomo e livre era um status que acompanhava a promessa de felicidade da modernidade.

Anteriormente, todos tinham um caminho a seguir, um ser divino a obedecer. Com o questionamento dessa submissão muitas pessoas se viram frente à inúmeras possibilidades, tantas, que não sabiam para aonde seguir. A grande demanda de informações, em constante transformação, carregava consigo valores morais que influenciavam e moldavam outros modos de comportamentos da sociedade. Felicidade, saúde, segurança, prazer, dentre outros focos de discurso voltados para os humanos, desenvolviam-se enquanto campos de produção linguística do individualismo. O exercício do relativismo de valores, desestabilizava verdades anteriormente constituídas e intensificava uma produção hedonista de seres voltados a si próprios. Desresponsabilizados dos outros, a modernidade produziu e estimulou comportamentos auto satisfatórios, individuais, indiferentes a aquilo que era externo de si (LIPOVETSKY, 2005).

Discursos cotidianos, como conteúdos da mídia, reforçam essas ideologias ao colocarem a pessoa como um indivíduo, fora da natureza, um ser teoricamente autônomo. Expressões como 'o nosso planeta', 'cuide dos nossos animais', 'a importância da natureza para as pessoas' materializa um meio ambiente que só se afirma como importante quando relacionado à existência humana. A linguagem implícita nesses discursos, aparentemente inocente ou preocupada com o meio ambiente, é carregada de uma ideologia individualista que molda os sujeitos numa específica forma de implicação política. Em muitas situações, defender os 'nossos recursos' mostra o desespero de determinadas camadas da população, especialmente aquelas envolvidas com a comercialização de elementos do meio ambiente, receosa de que 'suas' matérias primas se esgotem e, assim, a produção e o lucro sejam afetados (DIAS, 2002).

Com isso, torna-se importante evidenciar, nesses discursos, como as práticas ideológicas positivam ou negativam determinados raciocínios ao divulgarem específicas conexões de linguagem. A negação, no campo da educação ambiental, produzirá o que Grün (2005, p. 49) define como "[...] as áreas de silêncio [...] sendo elas não apenas conhecimentos que são abafados pelas classes dominantes, mas fruto de um dualismo lógico-estrutural presente na relação entre o "tipicamente moderno" e a "tradição" [...] o moderno toma seu lugar às custas de um esquecimento" daquilo que poderia ser a via para a preservação ambiental. Assim, para o autor, a contemporaneidade seria marcada “[...] por um sentimento de que atravessamos uma crise generalizada. Crise de valores, crise das ideologias, crise da (ou de) ética, crise dos paradigmas, crise da modernidade." (GRÜN, 2005, p. 62).

Para Tavares e Freire (2003), no contexto brasileiro, a crise recorrente do individualismo da modernidade se expressa por pequenos recortes do cotidiano: preocupação excessiva com a higiene pessoal (corpos malhados, dentes brancos, cabelos lavados, troca de roupas, banho obrigatoriamente diário, etc.) e a higienização local (de sua casa, seus objetos pessoais, etc.) que contrasta com a sujeira presente 'a partir da calçada'. A afirmativa 'a partir da calçada' expressaria um modo de pensamento que marca o absurdo da performatividade individualista, na qual as pessoas deixam de se importar com as sujeiras quando essas estão além de seus espaços individuais: nas ruas, jogam lixo no chão e poluem 
os ambientes nos quais não são considerados 'seus', portanto, não caberia ao 'indivíduo' preservar. Haveria uma dificuldade em saber o que é seu e o que é do outro e, ao mesmo tempo, uma necessidade intensa de se diferenciar criando um fictício ambiente individual no qual seríamos 'donos'. O contexto 'externo a nós', em muitos casos, acaba sendo interpretado como de responsabilidade do Estado ou do governo no qual votamos, sem nossa auto implicação com ele (TAVARES; FREIRE, 2003).

Aliado ao consumismo exacerbado, estaria a lógica da produtividade (TORRES; GUARESCHI; ECKER, 2017), derivada, também, da intensificação industrial, que incidiu sobre as (eco)lógicas do cotidiano. O aumento da produtividade dentro dos Estados e cidades, incluindo a prática da importação e exportação, proporcionou um aumento da diversidade de produtos nas prateleiras. Assim, no campo da produção de resíduos, ocorre uma possibilidade maior de consumo e de descarte, que se torna mais presente na vida das pessoas. $\mathrm{O}$ consumo exacerbado fica evidente quando um produto perde o caráter de objeto para uso e passa a ser denominado como objeto de consumo. Este acontecimento se exemplifica, quando a rapidez com que usamos determinado produto aumenta tanto a ponto de a rapidez com que descartamos se igualar. Como mostra Tavares e Freire (2003), o fato de cada pessoa produzir em torno de 1 quilo de lixo por dia (e em média 100 mil toneladas de lixo por dia no Brasil) denuncia a nossa atual lógica de vida.

A denominada modernidade enfatizou aspectos como o individualismo e a competitividade e, com a emergência da globalização, estabeleceu o que era riqueza, quais seriam os países considerados ricos, produzindo condições de possibilidade para o monopólio da natureza: quando os países competem entre si pela lógica da globalização, estamos remetendo a uma produtividade baseada em 'quem extrai mais da natureza' para aumentar sua capacidade de gerar produtos, lucro e, consequentemente, resíduos. Se levarmos o modo competitivo e produtivista ao extremo, teremos uma realidade totalmente contraria a visão sobre o que é preservar o meio ambiente.

A mídia, por exemplo, de acordo com Brügger (2005), contribui nesse modo de operar contrário a preservação da natureza, ao transmitir informações que distorcem as possibilidades de transformação do cotidiano. Segundo o autor, a divulgação de uma visão catastrófica da natureza, como um espetáculoecológico onde os recursos naturais estariam nos seus 'últimos suspiros', ou, ainda, o modo reducionista de apresentar o conceito dos 3R's (reduzir, reciclar e reutilizar), propaga informações que não apontam possibilidades sobre as possíveis modificações das (eco)lógicas diárias que as pessoas poderiam desenvolver para o cuidado da natureza. Focar, não apenas na reciclagem do lixo, mas, também, discutindo questões como o consumismo, o capitalismo e os modos de produção, apresentamse como vias que Brügger (2005) aponta para processos de autoeducação ambiental. Através das reflexões do autor, questiona-se: em um mundo cada vez mais globalizado, seria imaginável alterarmos os modos nos quais as pessoas se relacionam, sem que o prazer, o prestígio e o reconhecimento sejam centralizados num consumo-predatório de obtenção, uso, exibição e descarte material?

\section{Educação ambiental como via de autotransformação das (eco)lógicas cotidianas}

No contexto da indagação anterior, propõese a autoeducação ambiental como recurso de transformação das próprias (eco)lógicas cotidianas. No ponto de vista de Dias (2002, p. 38), “[...] o papel da educação atual, se não for o de resgatar o ser humano, será nenhum.” A chamada educação ambiental "[...] só foi criada pelo reconhecimento da ineficácia da educação" (DIAS, 2002, p. 44) formal, pois essa esqueceu de humanizar as pessoas e parece cada vez mais caminhar para o ensinamento do individualismo. Para o autor, precisamos incluir 
nos currículos escolares, em diferentes níveis de ensino, questionamentos acerca do papel do sujeito no mundo, dando-lhe informação necessária para que ele possa atuar com ética e responsabilidade. Talvez, como cita Pozo (2002, p. 26), a impressão que temos desta "decomposição da aprendizagem" se deve ao fato de, cada vez mais, estarmos sendo exigidos para obtermos uma grande demanda de conhecimentos. A cada segundo, surge uma nova informação que deveria estar sendo assimilada e compreendida.

A desumanização do conhecimento, que não possibilita os seres humanos estabelecerem uma relação de proximidade e sensibilização com aquilo que conhecem, remete a reflexão de Carla Tavares e Isa Freire. De acordo com Tavares e Freire (2003), não bastaria apenas o sujeito ter acesso à informação, seria preciso que ele adentrasse no processo de assimilação dessa informação: percurso no qual as pessoas entram em contato com um determinado conjunto de elementos desconhecidos e, a partir dessa interação, modificam suas percepções e sensações. Nesse raciocínio, que se propõe esta pesquisa-experiência, compreendendo que é a partir de um encontro de proximidade e sensibilização ao que é desconhecido que se construirá um conhecimento relacionado diretamente com aquilo que se conhece.

Para que a assimilação aconteça em uma pesquisa-encontro, pesquisa-experiência, na perspectiva da autoeducação ambiental, não seria suficiente apenas o sujeito ter contato com novas informações: é preciso que elas façam sentido para ele, que ele signifique de alguma forma e reelabore, junto com os conhecimentos que possui, os novos elementos que a ele são apresentados. A plasticidade humana facilita a capacidade de aprendizagem e flexibiliza aquilo que somos capazes de nos tornar. Habilidade presente nos diferentes animais, os processos de aprendizagem no humano se alteram de acordo com as diferenças culturais e demandas sociais localizadas. De qualquer modo, a educação ambiental surge como papel fundamental para que os sujeitos interiorizem ou incorporem a cultura do cuidado à natureza transformando a si enquanto habitantes e pertencentes de um mundo. $\mathrm{O}$ importante no processo de autoeducação ambiental, segundo Pozo (2002, p. 26), é incorporar a cultura de forma mais reflexiva, na qual refletiríamos sobre repeti-la, desmontando "[...] peça por peça para depois construí-la."

O desafio, segundo o autor, é que a educação hegemônica atual é muito mais repetitiva e memorística do que reflexiva. Somos, desde a infância, estimulados a sermos mais reprodutores de saberes e tradições, do que criadores de novos conhecimentos e costumes. A autotransformação também se torna difícil devido ao excesso de informações, principalmente, fragmentadas e superficiais, presentes nas diferentes mídias (virtuais, eletrônicas, impressas, dentre outras). As desigualdades sociais, em que algumas parcelas da população têm acesso à informação e outras não, também fragilizam e/ou enviesam as ideologias que são disseminadas junto às informações. $\mathrm{O}$ incentivo ao consumo e a categoria 'ostentação', enquanto estratégia de marketing, produz em determinados grupos aquilo que Tavares e Freire (2003) descrevem como a sensação de que os recursos naturais seriam inesgotáveis, já que o uso da natureza não seria relacionado diretamente com os produtos que se compram.

Para Pozo (2002, p. 40), a autoeducação ambiental com reflexo no coletivo só ocorrerá quando "[...] a cultura da aprendizagem direcionada para reproduzir saberes previamente estabelecidos [...]" der "[...] passagem a cultura da compreensão, da análise crítica, da reflexão sobre o que fazemos e acreditamos e não só o consumo, mediado e acelerado pela tecnologia, de crenças e modos de fazer fabricados fora de nós." A mudança das (eco)lógicas requer uma reconstrução da própria palavra ecologia, já que esta possui representação social muitas vezes errônea e enviesada num modo de pensar humano-centrado, consumista e individualista. 


\section{A experiência como processo metodológico de pesquisa e de autoeducação ambiental}

Com o objetivo de produzir uma pesquisaexperiência ${ }^{5}$ em autoeducação ambiental, com foco na transformação do pesquisador e de sua relação com a gestão de resíduos, o presente trabalho teve sua construção baseada em quatro principais etapas. A primeira etapa foi uma pesquisa de campo realizada a partir de quatro observações sistemáticas $^{6}($ BRITO,1994) na Avenida Coronel Aparício Borges (III Perimetral) em Porto Alegre, Rio Grande do Sul, Brasil, e quatro observações sistemáticas em uma universidade privada da mesma cidade. As observações tiveram como objetivo avaliar se o espaço público permite a autotransformação dos sujeitos para realizarem a separação de resíduos. Para isso, foram efetuadas caminhadas pelo pesquisador, com duração de 1 hora cada, em diferentes pontos da avenida e da universidade, visando avaliar se a estrutura delas possibilitava a separação dos resíduos como, por exemplo, ofertando latas de lixo diferenciadas. O percurso de caminhada foi acompanhado por relato gravado em voz, posteriormente analisado, totalizando 4 horas de percurso em cada local.

A segunda e terceira etapa foram desenvolvidas com a busca na internet (plataforma Google) e em uma biblioteca universitária (base de dados on-line da instituição) por informações sobre a separação de lixo na cidade de Porto Alegre, RS, Brasil. A busca se efetuou por marcadores como "reciclagem de lixo", "separação de resíduos", "gestão de resíduos", "Porto Alegre". O objetivo dessa etapa foi verificar se existe informação de fácil acesso, sobre a diferenciação entre materiais recicláveis, reutilizáveis ou inutilizáveis; se há caminhões de coleta seletiva que atuem pela cidade quando se quer mudar os próprios hábitos de gerenciamento do lixo como exercício (eco)lógico cotidiano. Foram enfatizados, na busca da plataforma Google, sites relacionados à gestão municipal que gerenciam a limpeza urbana da cidade de Porto Alegre.

A terceira etapa se constituiu com a imersão do pesquisador em uma associação de separação do lixo de Porto Alegre que possui convênio com o Departamento Municipal de Limpeza Urbana [DMLU] da cidade de Porto Alegre, RS, que recebe parte do material recolhido pelo caminhão da coleta seletiva do município. Articulado a essa etapa fora realizada uma entrevista semi-estruturada (TRIVIÑOS, 1987) com a responsável pela associação em que buscou-se saber informações mais detalhadas sobre a gestão dos resíduos humanos na cidade de Porto Alegre, através da perspectiva de quem trabalha com o lixo. Todas essas etapas foram desenvolvidas de modo articulado, tendo como ponto de referência a intensão do pesquisador em auto educar-se (eco)logicamente.

Inspirada em produções de conhecimento pósestruturalistas, a noção de pesquisa-experiência, que embase a construção desse artigo, é influenciada por discussões do autor Michel Foucault. Ao utilizar a expressão Empirista cego, Foucault (2006) trazia elementos sobre sua atitude de pesquisador. Em entrevista concedida em 1977, o autor comenta sobre não ter produzido uma teoria geral, nem tampouco um instrumento no qual pudesse se fixar. Posicionando-se sobre a produção do pesquisar, Foucault diz: "[...] eu tateio, fabrico, como posso, instrumentos que são destinados a fazer aparecer objetos." (FOUCAULT, 2006, p. 229). Desse modo, as experiências da presente discussão, posteriormente relatadas como resultado e reflexão de um exercício de pesquisa, emergem articuladas

\footnotetext{
${ }^{5}$ Trabalho realizado dentro da Disciplina "Prática Interdisciplinar em Psicologia". Aprovado pela Faculdade de Psicologia (FAPSI) da Pontifícia Universidade Católica do Rio Grande do Sul (PUCRS). Por se tratar de um trabalho com o intuito exclusivamente de educação e ensino, de acordo com a Resolução n ${ }^{\circ}$ 510, de 07 de abril de 2016, não fora registrada e nem avaliada pelo sistema CEP/CONEP.

${ }^{6}$ Não havia roteiro prévio para as observações.
} 
as fundamentações teóricas sem necessidade de seguir roteiros analíticos previamente estabelecidos. Tateando elementos e fabricando objetos para o pensamento (ECKER, 2018), a experiência do pesquisar emergiu na construção desse trabalho como possibilidade de transformação, pela própria vivência no campo temático, das (eco)lógicas cotidianas do pesquisador. Assim, a discussão dos materiais se propõe a compartilhar possibilidades de ações no campo da educação ambiental, articulando reflexões a partir da experiência sobre aspectos subjetivos e estruturais envolvidos na transformação de (eco)lógicas cotidianas.

\section{Resultados e reflexões: seres humanos e paradigmas educativos-ambientais localizados}

Anatureza parece imersa em um olhar humanoque a determina como fonte de riqueza ${ }^{7}$, especialmente, incidido por empresas. Aquantidade de produtos que há no comércio, utilizando matérias primas naturais, aponta elementos sobre essa situação. Através da pesquisa-experiência encontraram-se campanhas na mídia, nos sites da internet pesquisados, que incentivam o que Grün (2005) nomeia como sensibilização ecológica. Contudo, na entrevista com a responsável pela associação dos catadores de lixo foi exposto que, quando o governo de Porto Alegre criou a coleta seletiva, ele foi responsável pela grande divulgação que ocorreu, mas, relata não ter sido suficiente, pois atingiu apenas os bairros de classe média, média alta, mantendo, assim, muitas pessoas desinformadas. A conexão entre capital e natureza, nesse exemplo, remete a uma reflexão sobre o dinheiro também como via para melhorar as condições de lidar com a escassez da natureza, pelo fato de a própria informação pública sobre a gestão dos resíduos humanos tornar-se um produto acessível a específicos públicos.
Muitos materiais sobre reciclagem foram encontrados no site da plataforma Google e na biblioteca da universidade, sendo a divulgação na mídia um resultado visível. Entretanto, isso não significa que as pessoas realmente tenham transformado seus comportamentos. No campus da universidade analisada, uma entidade que possui o sistema de coleta seletiva, fora observado que as pessoas não separam corretamente o lixo e, frequentemente, há mistura de materiais que poderiam ser reaproveitados junto com resíduos inutilizáveis. A presença de apenas dois tipos de lixeiras fora apontado como um fator que dificulta a autotransformação da (eco)lógica cotidiana, pois o ideal, segundo a associação de lixeiros, seria que dividíssemos, no mínimo, entre três lixeiras: recicláveis, não-recicláveis e orgânicos. Conjuntamente, o fato de o lixo orgânico ser um composto que tem um benefício importante a natureza, se usado corretamente (na adubagem), não é aplicado no dia-a-dia da instituição. Não há, como constou a caminhada pelo campus, o uso do lixo orgânico como adubo nos canteiros da universidade ou em outros espaços da instituição.

Vivenciar a pesquisa-experiência constata, também, que uma mudança das (eco)lógicas cotidianas para a gestão dos resíduos possibilitaria modificar o modo como o gerenciamento do lixo ocorre no dia-a-dia. Entretanto, para que isso ocorra, é necessário atentar para as ideologias cotidianas presentes nos discursos sobre a natureza que a nomeiam como "nossa". Atento ao processo de transformação do próprio pesquisador, durante a vivência da pesquisa-experiência, flagrei-me falando ou pensando "temos que cuidar da nossa natureza." A responsável pela associação de catadores alertou para isso quando diz que: “[...] o catador é um agente protetor da natureza, mas, se formos pensar sobre isso que dizemos, perceberemos que nós fazemos

\footnotetext{
${ }^{7}$ Cabe destacar a complexidade dessa afirmação, pois, ao situar o ser humano, também ele um elemento da natureza, como produtor de um olhar do capital sobre a natureza, consequentemente estamos remetendo a um humano que se analisa enquanto capital. Essa incidência de um olhar econômico sobre si, pode produzir uma multiplicidade de subjetividades que se situariam como possibilidade de riqueza e/ou matéria prima explorável.
} 
parte da natureza, ou seja, eles protegem a si mesmos." Portanto, ressituar e recolocar afirmações do dia-a-dia, compreendidas como 'naturais', abrese como possibilidade de transformação das (eco) lógicas cotidianas. Reciclar o modo de pensar, transformando a relação subjetiva com a gestão de resíduos, estará protegendo a nós mesmos: protegendo-nos de alagamentos, proliferação de doenças, mantendo recursos como água, ar e energia disponíveis para nós e para as gerações futuras, protegemos as matérias primas, tão preciosas, no presente e para o futuro.

Cabe destacar que a transformação subjetiva da (eco)lógica cotidiana também requer ser situada em uma localização espaço-temporal e histórica. Desse modo, há de se levar em consideração aspectos regionais, climáticos, histórico-culturais de cada contexto e sujeito para que transformações das (eco) lógicas cotidianas sejam pensadas. Os problemas com o meio-ambiente estão atingindo todo o mundo, não apenas Porto Alegre e, ao encontrar o documentário do Al Gore, durante a pesquisa na plataforma Google, tem-se como elemento de discussão que os países ditos de 'terceiro mundo' sofrem um impacto muito maior nas mudanças climáticas (UMA VERDADE, 2006). Ao discutir o aquecimento global, o documentário evidencia que os Estados Unidos, país considerado de 'primeiro mundo', se omite em muitos pontos referentes aos problemas ambientais e, mesmo o documentário apresentando em momentos uma leitura sensacionalista, coloca em discussão a importância de situar os debates sobre o meio ambiente sob recortes territoriais e histórico-culturais.

O recorte das especificidades de localização, que pensa o sujeito possível de autoeducação ambiental numa localidade histórico-cultural, ficou evidente quando fora proposto a presente pesquisaexperiência no campo de atuação da psicologia. Ao compartilhar a pesquisa com colegas da área, houveram questionamentos sobre qual a relação entre ecologia e psicologia. Compreendeu-se, através dessas indagações, que educação ambiental ainda é um tema pouco recorrente na área, sendo a produção de conhecimento da psicologia restrita em pensar a relação da subjetividade com o meio ambiente. "Porque você discutirá a problemática do lixo se a psicologia não trabalha com isso?". Supõese, através de questionamentos nesse sentido, que eles emergem como reflexo de um ensino acadêmico, médio e fundamental, que fragmenta seres humanos da natureza; um ensino que prioriza questões quantitativas do que qualitativas e, ainda, especialmente na área da psicologia, compreende as subjetividades como externas a um meio ambiente, descontextualizadas, numa leitura individualizada e patologizante dos sujeitos (GUARESCHI et al., 2014).

Aspectos humanos, comoética e responsabilidade social, pouco se relacionam com a produção de subjetividade que pude experenciar e colocar em discussão na formação em psicologia. Mesmo não sendo possível generalizar a complexidade de formações existentes no Brasil, os trabalhos acadêmicos e discussões nas disciplinas que presenciei não eram compreendidos como espaços para que os(as) estudantes discutissem questões que demandavam atenção no nosso país, como desigualdades socioeconômicas, debates sobre política, aspectos raciais, de gênero, sexuais, assim como, a própria questão da poluição e de outros aspectos ambientais. Os trabalhos acadêmicos eram formulados apenas para 'passar no semestre' como garantia de 'uma boa nota'. Consequentemente, 'um bom currículo' não era relacionado a responsabilidade social ou a ética, o que aponta para uma problemática que caberia aos espaços de formação propiciar reflexões integrando formação profissional e implicação ético-ambiental, principalmente, no que se refere a uma psicologia atuante na produção do bem-estar de si e da população como um todo, relacionada a natureza.

Durante o processo da pesquisa-experiência, indagações foram sendo produzidas. Uma delas remete sobre a forma como as pessoas se compreendem no meio ambiente. Pelas perguntas 
que eram formuladas, questionando a proposta de autotransformação das (eco)lógicas cotidianas, a mais desafiadora era auxiliar as pessoas a se pensarem enquanto seres pertencentes a uma cadeia, a um ciclo da natureza, no qual todos os seres vivos se inter-relacionam. Um exemplo claro desse pensamento fora dado em uma palestra, na qual o palestrante relatava sobre o impacto de usarmos sabão em pó ou xampu que não fossem biodegradáveis. Depois que usamos esses produtos, eles entram em contato com a água e essa é despejada nos canos e levada para os rios, lagos e mares. A partir de um produto químico utilizado na fabricação de grande parte dos xampus e sabões em pó, a água perde o que é chamado de "tensão superficial" e, consequentemente, as aves que antes flutuavam não conseguem mais exercer essa função e afundam na água. Os insetos, também acabam sofrendo essas conseqüências, pois perdem a função de flutuação. Assim, expressava o palestrante, animais que antes os patos comiam se multiplicarão e os animais que se alimentavam de insetos entrarão em extinção, por não terem mais alimento. A natureza, enquanto ciclo, ao não ser relacionada com os humanos e sua existência no mundo, a partir dos questionamentos que me eram formulados, remete a uma subjetividade individualista, caracterizada pela dificuldade de perceber e se preocupar com os outros e seu entorno.

\section{Resultados e reflexões: humanos individualistas e ideologias de consumo}

A globalização produz um maior número de informações, essas que muitas vezes se contradizem e fazem com que os sujeitos que as ouçam não saibam em qual acreditar ou se tornem confusos perante as mesmas. De um lado, recebemos a mensagem de que devemos comprar, de outro, dizem que devemos parar de consumir. A partir de reflexões pela pesquisa-experiência, compreende-se que uma das dificuldades em as pessoas reciclarem seus lixos e, principalmente, se preocuparem com os outros e seu entorno se deve a valores que aprenderam (ou que não aprenderam) no processo educacional. Essa educação, não se dá apenas nas escolas, mas em casa, com os amigos, pelas mídias, nas ruas, pelo modo como se organizam as vidas, como os humanos se relacionam com a natureza, com os outros animais e dos humanos entre si.

A mídia incentiva o consumo, ela vende a idéia de que quem possui e quem compra será feliz. Ao comentar com uma psicóloga sobre reflexões dessa pesquisa, ela expõe: "a publicidade é a ciência que cria em nós a angustia de não ter" e, sua afirmação, remete as bibliografias pesquisadas na biblioteca da universidade. Nela, dois livros foram encontrados com discussões acerca de comportamentos modernos e consumo. Nos sites que trabalham a questão do lixo, na plataforma Google, apenas um fala que devemos parar de consumir, o restante focaliza na reciclagem sem apontar para o consumo excessivo. Esses exemplos de informações, apesar de não refletirem uma totalidade, dificultam as pessoas de mudarem seu consumo, pois focam apenas na reciclagem e não no comportamento de consumo que sustenta a produção excessiva de resíduos. De acordo com o posicionamento da responsável pela associação de catadores de lixo, o comportamento de não se preocupar com os resíduos e para onde eles vão "é egoísmo". Nas suas palavras, "o que a pessoa considera que tira de dentro da sua casa? É lixo. As pessoas têm isso, não imaginam que por trás daquele lixo tem alguém, e para aquelas pessoas não é lixo, é material de trabalho, porque o lixo, para algum lugar vai".

Segundo crítica de Martell (1994), uma sociedade sustentável será praticamente impossível se o consumismo estiver presente. Para Ekins (1998), desde que a indústria aumentou sua produção de modo extremo, com o objetivo de que a população consumisse, a ação de comprar é enaltecida como fonte de bem-estar, sinônimo de felicidade, como ferramenta estratégica para manutenção do próprio consumo. Então, como se 
posiciona Layrargues e Castro (2005), as discussões sobre a temática do lixo deveriam ser geradoras de reflexões mais profundas sobre o nosso modo de viver individualista baseado em um consumo competitivo. Para o autor, a reciclagem não deveria ser interpretada como uma atividade fim, mas, sim, como um início de uma caminhada contestadora dos comportamentos modernos. Nessa lógica, como vivência de um processo de autoeducação ambiental, algumas perguntas emergem pela pesquisa-experiência: o que, em nossa educação, nos torna pessoas individualistas? Porque consumir traria felicidade? Quem nos ensina que consumir é o que satisfaz as necessidades humanas? Consumir seria uma necessidade humana?

As bibliografias encontradas na internet (plataforma Google) e na biblioteca universitária produziram diversas indagações, ao mesmo tempo que apontaram sobre a impossibilidade do ser humano viver sem consumir ou produzir lixo, minimamente. Em um dos sites visitados, foi possível perceber que muitas empresas aproveitam os problemas ambientais para lançar produtos e lucrar a partir de questões problemáticas ao meio ambiente. Semelhante as datas comemorativas, como a páscoa, o dia das mães e outros eventos, a indústria do comércio lucra em cima daquilo que emerge no social. $\mathrm{O}$ apelo publicitário se utiliza das datas festivas e eventos climáticos como via para transformar elementos da vida em capital: seja pela venda de produtos recicláveis para satisfazer crianças, estudantes, homens e mulheres; pela criação de tecidos 'naturais'; empresas que fazem propaganda por serem 'ecologicamente corretas'; instituições que 'plantam árvores' como estratégia de marketing; o calor, a seca ou as tempestades tornam-se justificativas para a criação de produtos; dentre outras formas de capitalização da natureza.

Osimples fato dehaver, nos materiaispesquisados, um ocultamento de discussões sobre o consumo, em detrimento do tema da reciclagem, remete a ideia de Grün (2005) sobre as áreas de silêncio dos currículos. Esse silenciamento acobertaria comportamentos que ocorrem, como o de consumo excessivo, mas, que não é debatido amplamente para não ser questionado e alterado. Manter em silenciamento o tema do consumo preserva determinados grupos, que sobrevivem a base do consumo de outros. Não questionar nossa própria existência, e o modo como o consumo se atravessa nela, impossibilita exercícios de autoeducação ambiental para transformação das (eco)lógicas cotidianas. Na 'naturalização' do cotidiano, o consumo torna-se uma tradição que continuamos seguindo de forma inquestionada, reproduzindo-o, sem desestabilizar esse comportamento com outros ângulos de análise. A mesma 'naturalização' se refere a nossa relação com os outros e o entorno: aprendemos que devemos cuidar da limpeza de nossa casa, devemos 'cuidar' da aparência, mas, a cidade, as ruas, o meio ambiente, não nos é entendida como de nossa responsabilidade.

Essa perspectiva individualista, permeada por naturalizadas ideologias de consumo, inviabiliza e limita às pessoas de mudarem, agirem e reivindicarem outros modos de ser e estar no mundo, na relação com a natureza. Desse modo, sob uma perspectiva individual e enviesada pelo consumo, muitas das problemáticas ambientais acabam sendo interpretadas como 'culpa do governo' e a própria gestão dos resíduos é subjetivada nos sujeitos como algo externo a si, não pertencente às ações humanas. $\mathrm{Na}$ entrevista com a responsável pela associação de reciclagem, por exemplo, se tensionou os limites tênues entre aquilo que seria de um suposto indivíduo e o que remete A um coletivo. Neste discurso da coordenadora é possível evidenciar o paradoxo da própria existência humana: “[...] a gente, na verdade, também presta um serviço a cidade, porque, aonde eles colocariam esta quantidade de lixo que nós produzimos?" (grifo nosso). 


\section{Resultados e reflexões: gerir resíduos por autotransformação das (eco)lógicas cotidianas}

No processo aqui relatado, de transformação das (eco)lógicas cotidianas do pesquisador, os questionamentos sobre a existência humana, na relação com a natureza, se fizeram necessários para que outras respostas sobre o viver fossem produzidas. Compreender que os seres humanos não são seres individuais, mas, sim, relacionais e interdependentes de outros seres vivos, afeta o modo como nossa subjetividade produz comportamentos. No campo da gestão de resíduos, para que haja mudanças, os seres humanos terão que entender que a história do lixo não acaba quando jogamos ele fora (ONG LIXO CONSULTING, 2007), ou seja, há muitos seres vivos envolvidos no processo pósdescarte, inclusive, humanos.

Os materiais encontrados na plataforma Google e na biblioteca da universidade apontam a necessidade de se refletir sobre o meio ambiente, mudando comportamentos, para não se chegar a um ponto no qual os recursos naturais extinguirão totalmente. Nos materiais disponíveis on-line, que propõem mudanças, indica-se que ainda é possível mudar o comportamento humano para que outros desastres ambientais sejam evitados. Orientações disponíveis na internet sugerem a importância de uma reflexão ética, com responsabilidade social, para transformação das (eco)lógicas cotidianas. Informações sobre como se gere os resíduos, por exemplo, fora encontrado na bibliografia de diferentes maneiras. Pelo panorama registrado, há uma priorização de informações sobre o processo de reciclagem, em contraponto a uma quantidade menor de materiais sobre a diminuição do consumo ou referente a estratégias para redução da produção de lixo. No campo da gestão de resíduos, a separação dos materiais, em um momento, fora encontrada dividindo o lixo em “domiciliar" e "orgânico". Já, em outro material, se separava por "[...] recicláveis, hospitalar, domiciliar, orgânico e dejetos."
Entende-se que a localização territorial e a atuação política de cada cidade, e seus respectivos gestores, impactará o modo como se desenvolverão práticas de separação de lixo em cada território. Contudo, além da iniciativa e busca por ações de separação, percebe-se, pelo processo da presente pesquisa-experiência, que a produção de uma autoeducação ambiental requer mudanças que são também subjetivas. Indagações, como ferramentas para estimular transformações subjetivas, podem ser estratégias importantes de autoeducação ambiental: por qual motivo habitamos o mundo? Porque destruímos a natureza? É possível vivermos sozinhos, sem dependermos de nenhum outro ser vivo? Por que ficamos indiferentes a alguém que passa fome, morre por desnutrição ou por alguma doença oriunda do meu próprio lixo que é despejado no meio ambiente?

Comportamentos compreendidos como tradicionais, no cotidiano de gestão dos resíduos, e hábitos tidos como 'naturalizados' devem ser questionados. Ações diárias, como ir ao supermercado levando uma sacola de pano de casa para não produzir mais lixo com as sacolinhas de plástico, imprimir folhas frente e verso, usar materiais oriundos de resíduos reciclados, ficar atento a ideologias do 'ecologicamente correto', exigir lixeiras diferenciadas e medidas de coleta seletiva, no próprio bairro ou ambiente de trabalho, podem ser ações sutis que transformam em ação o cuidado da natureza. Assim, através das reflexões vivenciadas pela pesquisa-experiência foi possível analisar a necessidade de algumas mudanças no entorno do próprio pesquisador, como solicitar que o condomínio que ele habita implementasse a coleta seletiva, pesquisar e divulgar os horários dos caminhões de coleta da prefeitura para os(as) moradores(as), propor no trabalho que materiais escritos fossem enviados por e-mail e não impressos, cessar o uso de sacolas plásticas no supermercado, desenvolver uma tabela de materiais recicláveis a partir do contato com a associação de reciclagem, dentre outras, que modificaram a (eco)lógica cotidiana em prol de algo coletivo. 
Entende-se, que uma modificação mais ampla e estrutural envolvendo, não apenas moradores(as), mas a cidade como um todo, requer ações da gestão governamental, assim como, da sociedade organizada. Háuma grande variedade de produtos nos supermercados e a utilização de descartáveis é cada vez maior. Os produtos descartáveis são encontrados com facilidade em lancherias, supermercados e bares porque proporcionam comodidade a quem os utiliza. Colheres, copos, garfos, facas de plástico que são utilizados apenas uma vez e depois viram lixo. Organizar-se socialmente é considerar os espaços públicos, que oferecem utensílios descartáveis, como agentes passíveis de intervenção estrutural para que se modifiquem comportamentos cotidianos, o que resulta em transformações que são, também, subjetivas. Contudo, não se deve pensar que a separação do lixo é o suficiente para resolver a questão ambiental, pois, apesar de haverem associações de reciclagem, não há um número suficiente que comporte a demanda de lixo que se produz diariamente. A própria frequência do consumo precisa ser reavaliada. Como vemos na fala da responsável pela associação de catadores, referente à coleta seletiva:

[...] só os bairros nobres são atingidos. E, apenas nesses bairros em que é feita a coleta já é juntado material suficiente para todas as unidades de separação que existe em Porto Alegre e ainda sobra material. Então poderia haver hoje umas trinta cooperativas e, atualmente, existem 13 (RESPONSÁVEL PELA ASSOCIAÇÃO DE CATADORES).

A transformação da (eco)lógica cotidiana de gestão dos resíduos pode ser exercitada, por exemplo, carregando garrafinhas de água reutilizadas, ao invés comprar sempre uma nova, ou levando talheres de casa e caneca para o café, sempre que possível. Avaliar os produtos que se consome nos supermercados pode ser outra estratégia, já que $40 \%$ deles já é lixo antes mesmo de serem consumidos (ONG LIXO CONSULTING, 2007). Como, por exemplo, aquelas embalagens que vem com um plástico em volta, com uma tampa de plástico, com um lacre de alumínio ou invólucro de papelão. No supermercado, na sessão dos legumes e verduras, é possível não utilizar saquinhos plásticos em muitos alimentos, principalmente, os que são vendidos por unidade e não por peso. No momento de ensacar os produtos comprados, pode-se solicitar ao(a) empacotador(a) reduzir o número de sacolas, usando ao máximo a capacidade de cada saco. Colocar as compras na bolsa, em uma mochila ou carregar na mão, quando possível, pode ser outra ação de autoeducação ambiental.

As mudanças na (eco)lógica cotidiana são relevantes porque a capacidade de sujar ainda é maior do que a de limpar. Como vemos no comentário da responsável pela associação de reciclagem: “[...] são muito poucos [ela fala dos caminhões de coleta seletiva do DMLU de Porto Alegre] que atingem a cidade. Eles estão há dois anos e pouco nessa nova gestão e até hoje não foi comprado caminhões, então tu imagina em dois anos rodando diariamente o desgaste" (parênteses nosso). Ao ser questionada o porquê ela achava que eles não haviam investido em novos caminhões, responde: "Acho que é falta de recursos, verba. Por que se tem um gasto. Hoje nós temos uma frota de caminhões sucateados."

Nessa citação, exemplifica-se ações para modificação de uma (eco)lógica cotidiana mais ampla e estrutural envolvendo, não apenas moradores(as) e indivíduos, mas, a gestão governamental do município. Desse modo, é preciso analisar o tema da gestão dos resíduos, não apenas, como uma ação individual cotidiana, mas, também, como um exercício político de gestão necessária. Não basta, somente, divulgar reflexões na mídia ou fazer campanhas simbólicas, é preciso investir concretamente em infraestrutura, políticas públicas, que respondam a demanda atual de resíduos que a população produz diariamente (LAYRARGUES, CASTRO, 2005). 
Nesse panorama, um resultado relevante que a presente pesquisa-experiência evidencia é a impossibilidade de se pensar uma autoeducação ambiental e transformação das (eco)lógicas cotidianas sem que haja uma modificação externa ao sujeito, mais ampla e estrutural. O impacto de uma gestão governamental para o exercício ambiental cotidiano ficou visível quando, em uma das observações, o pesquisador caminhou durante uma hora na III Perimetral de Porto alegre e só avistou uma lixeira na calçada após 30 minutos caminhando. Durante essa meia hora, já teria havido a possibilidade de jogar o lixo no chão, ao não ser encontrado nenhuma lixeira. O que impressiona, nessa vivência, é que a avenida é uma obra recente na cidade e não foi planejada com a inserção de lixeiras nela. E não está se falando em ter lixeiras para coleta seletiva, neste caso da observação, não havia nenhuma lixeira. Um fato interessante nesse trecho da observação é o seguinte relato: "[...] neste momento, eu já estou caminhando há 49 minutos, passei por apenas duas lixeiras na calçada, mas por 20 outdoors de propaganda, sem contar placas de lojas e afins." Essa reflexão, aponta sobre uma primazia do comércio e do consumo, na gestão dos espaços públicos, em detrimento de uma preocupação com o meio ambiente e a gestão dos resíduos humanos.

\section{Considerações finais}

O presente texto tinha como objetivo compartilhar o resultado de uma pesquisaexperiência sobre exercícios (eco)lógicos possíveis de autoeducação ambiental, no tema da gestão dos resíduos humanos. Para isso, o pesquisador se dispôs a vivenciar experiências no campo do tema através de observações no espaço público e em um ambiente universitário, com pesquisa na plataforma Google e em uma biblioteca universitária, assim como, realizando entrevista com a responsável por uma associação de reciclagem de lixo na cidade de Porto Alegre. Durante o percurso, foi possível articular o que era vivido na experiência com o tema do meio ambiente, refletindo sobre os paradigmas educativo-ambientais e as ideologias de consumo e de individualismo que permeiam o cotidiano humano. Através de elementos emergentes no campo da pesquisa, foi possível colocar em análise a educação ambiental, considerando-a enquanto via de transformação das (eco)lógicas cotidianas, alguns de seus impasses, como os aspectos subjetivos ou estruturais envolvidos.

As modificações das (eco)lógicas cotidianas, na relação com o meio ambiente, articulam uma complexidade de fatores e, pela presente discussão, compreende-se a importância de transformações subjetivas e estruturais para a preservação da natureza. Como inerente a toda mudança, enquanto estratégia de transformação, é necessário colocar em análise o modo com que se vive e se relaciona consigo mesmo e com o meio ambiente. Esse exercício, que requer, também, uma transformação subjetiva, exige que o ser humano se vigie diariamente, não como forma de controle, mas, como exercício para construção de outros hábitos possíveis. Como escreve Lévi-Strauss (2005, p. 230), "[...] a partir do momento em que o homem não conhece mais limites para o seu poder ele próprio acaba por destruir-se." Com a gestão dos resíduos humanos, poderíamos pensar da mesma forma. Se nós humanos continuarmos a consumir sem limites, extinguindo matérias primas, animais e seus habitats, corre-se o risco de uma autodestruição, pois todos esses elementos vivos compõem nosso próprio meio ambiente de existência.

O que era nomeado como lixo, através da presente pesquisa-experiência, tem seu significado ressignificado. Os resíduos, agora situados em uma complexidade deles próprios (secos, orgânicos, inutilizáveis, recicláveis, dentro outros), se situam como possibilidade, até, de serem geradores de renda para determinados grupos, como o são para os catadores e recicladores da associação estudada. Assim, a temática da educação ambiental, enquanto inerente para o bem-estar dos seres humanos e demais 
seres vivos, tem sua pertinência para benefícios individuais e coletivos. Indivíduo e coletivo que se mostram, a partir dos materiais discutidos, como elementos indissociáveis, necessários de serem colocados em discussão para a autotransformação das (eco)lógicas cotidianas.

\section{Referências}

BRITO, A. Observação directa e sistemática do comportamento. Lisboa: Edições FMH, 1994.

DIAS, G. F. Pegada ecológica e sustentabilidade humana. São Paulo: Gaia, 2002.

ECKER, D. D. Direitos sociais e acompanhamento terapêutico: problematizações através de desenhos. Aurora: revista de arte, mídia e política, São Paulo, v.11, n.32, p. 95-109, jun./set. 2018. Disponível em: http:// revistas.pucsp.br/aurora/article/view/31984. Acesso em: 20 nov. 2018.

EKINS, P. Uma noção subversiva. O Correio da Unesco, Rio de Janeiro, v. 26, n. 3, p: 6-9, 1998.

FOUCAULT, M. Poder e saber. In: FOUCAULT, Michel. Ditos e escritos: estratégia, poder-saber. Rio de Janeiro: Forense Universitária, 2006, p. 223 - 241. v. 5.

GRÜN, M. Ética e educação ambiental: a conexão necessária. 9. ed. São Paulo: Papirus, 2005.

GUARESCHI, N. M.; GUARESCHI, N. M. F.; REIS, C.; ECKER,D.D.;MACHRY,D.S.F.Formaçãoempsicologia: o princípio da integralidade e a teoria da autopoiese. Revista Psicologia e Saúde, Campo Grande, v. 6, n. 1, p. 18-27, jun. 2014. Disponível em http://pepsic.bvsalud. org/scielo.php? script $=$ sci_arttext\&pid $=$ S2 177-093 $\mathrm{X} 2014000100004 \& \operatorname{lng}=\mathrm{pt} \& \mathrm{nrm}=$ iso. Acesso em: 20 nov. 2018.

UMA VERDADE inconveniente. Direção: Davis Gugenheim. EUA: Paramount Pictures, 2006. Longametragem (100 min.), color.
HARTMANN, V. M. Memórias na sustentabilidade das águas do Rio M’Boicy. 2017. Trabalho de Conclusão de Curso (Especialista em Educação Ambiental) Programa de Pós-Graduação em Educação Ambiental da Universidade Federal da Integração Latinoamericana, Foz do Iguaçu, 2017.

HÜNING, S.; SCISLESKI, A. Ressonâncias de uma epistemologia crítica foucaultiana em psicologia social. Psicologia \& Sociedade, v. 30, n. 1, 2018.

LAYRARGUES, P.P; CASTRO, R. S. (org.). Educação ambiental: repensando o espaço da cidadania. São Paulo: Cortez, 2005.

LÉVI-STRAUSS, C. De perto e de longe. Rio de Janeiro: Nova Fronteira, 2005.

LIPOVETSKY, G. Os tempos hipermodernos. São Paulo: Editora Barcarolla, 2005.

ONG LIXO CONSULTING. Rio de Janeiro: RJ. 2007. Disponível em: http://www.lixo.com.br. Acesso em: 20 nov. 2018.

MARTELL, L. Ecology and society: an introduction. Cambridge: Polity Press, 1994.

POZO, J. I. Aprendizes e mestres: a nova cultura da aprendizagem. Porto Alegre: ArtMed, 2002.

SOFFIATI, A. Fundamentos filosóficos e históricos para o exercício da ecocidadania e da ecoeducação. In: LOUREIRO, C. F. B.; LAYRARGUES, P. P.; CASTRO, R. S. (org.). Educação ambiental: repensando o espaço da cidadania. 4. ed. São Paulo: Cortez, 2008. p. 23 -68.

TAVARES, C; FREIRE, I. M. Lugar do lixo é no lixo: estudo de assimilação da informação. Ciência da Informação, Brasília, v.32, n. 2, p. 125-135, maio/ago. 2003. Disponível em: http://re vista.ibict.br/ciinf/article/ view/1012. Acesso em: 22 nov. 2018.

TORRES, S.; GUARESCHI, P. A.; ECKER, D. D. $\mathrm{O}$ teatro de rua como via política de mídia radical. Argum, Vitória, v. 9, n. 2, p. 120-132, maio/ago. 2017. Disponível em: http://periodicos.ufes.br/argumentum/ article/view/15423/11900. Acesso em: 22 nov. 2018.

TRIVIÑOS, A. N. S. Introdução à pesquisa em ciências sociais. São Paulo: Atlas, 1987. 